\title{
Analisis PS dalam Membantu Self-Regulation Pada Pemecahan Masalah Matematika Mahasiswa Prodi Informatika
}

\author{
Lisda Ramdhani ${ }^{*}$, Ramli ${ }^{2}$, Ardi Rahmawan ${ }^{3}$, Muslimin $^{4}$ \\ 1,2,3,4 STKIP Harapan Bima, Kota Bima, NTB \\ *Email: Lisdaramdhani1227@gmail.com ${ }^{1}$,ardi.rahmawan2019@gmail.com ${ }^{3}, \underline{\text { musliminppsunm@gmail.com }}$
}

\begin{abstract}
The purpose of this study was to describe and explore private speech in helping students self-regulation in solving mathematics problems for students of the Informatics Education Study Program. The approach used in this research is a qualitative approach, with the type of descriptive research. The research subjects were 12 students from 50 Informatics education students. The instruments used are description tests, interviews, questionnaires and observations as well as audio-visual recordings. Data analysis techniques were carried out in three ways, namely, data reduction, data presentation and drawing conclusions. There are three stages in this research, namely the preparation, implementation and report stages. The results of the research in the form of interviews and observations in general are obtained that private speech in its role is very helpful for self-regation, where private speech plays an important role in controlling student attitudes, and increasing academic values and student concentration. Various self-regation experienced by students but it does not become a negative influence on the behavior and daily life of students. Selfregulation experienced by students is controlling student attitudes and behavior when using private speech. Students always do assignments responsibly and on time using private speech, as many as $25 \%$ of students choose strongly agree, 58\% choose agree and $17 \%$ choose less agree. The use of private speech makes students lazy to study, as many as $33 \%$ of students chose not to agree and $67 \%$ of students did not agree. Good self-regation makes students focus on solving problems, as many as $92 \%$ of students choose strongly agree and $8 \%$ of students choose agree. Academic value increased by using private speech with good self-regulation, as many as $17 \%$ of students strongly agreed and $58 \%$ of students agreed and $25 \%$ of students did not agree. Private speech is done when they find it difficult to solve problems, as much as $25 \%$ choose strongly agree, $42 \%$ agree and $33 \%$ disagree. Self-regation affects academic scores as much as $33 \%$ choose strongly agree, $42 \%$ agree and $25 \%$ disagree.
\end{abstract}

Keywords: Private Speech, Self-Regulation, Problem Solving

\begin{abstract}
Abstrak
Tujuan penelitian ini adalah untuk mendeskripsikan serta mengeksplorasi private speech dalam membantu selfregulation mahasiswa pada pemecahan masalah matematika mahasiswa Program studi Pendidikan Informatika. Pendekatan yang digunakan dalam penelitian ini adalah pendekatan kualitatif, dengan jenis penelitian deskriptif. Subjek penelitian 12 Mahasiswa dari 50 Mahasiswa pendidikan Informatika. Instrumen yang digunakan adalah soal tes uraian, wawancara, angket dan observasi serta rekaman audio visual. Tekhnik analisis data dilakukan dengan tiga cara yaitu, Reduksi data, penyajian data dan penarikan kesimpulan. Ada tiga tahapan dalam penelitian ini yaitu tahap persiapan, pelaksanaan dan laporan. Hasil penelitian beruapa wawancara dan observasi secara garis besar diperoleh bahwa private speech dalam perananannya sangat membantu self-regation, dimana private speech berperan penting dalam mengendalikan sikap mahasiswa, dan meningkatkan nilai akademik serta konsentrasi mahasiswa. Berbagai self-regation yang dialami oleh mahasiswa namun hal tersebut tidak menjadi pengaruh negatif bagi prilaku maupun keseharian mahasiswa. Self regulation yang dialami mahasiswa adalah kontrol sikap dan prilaku mahasiswa pada saat menggunakan private speech. Mahasiswa selalu mengerjakan tugas dengan penuh tanggung jawab dan tepat waktu dengan menggunakan private speech, sebanyak 25\% mahasiswa memilih sangat setuju, 58\% memilih setuju dan $17 \%$ memilih kurang setuju. Penggunaan private speech membuat mahasiswa malas belajar yaitu sebanyak $33 \%$ mahasiswa memilih kurang setuju dan $67 \%$ mahasiswa tidak setuju. Self-regation yang baik membuat mahasiswa fokus dalam menyelesaikan soal, sebanyak $92 \%$ mahasiswa memilih sangat setuju dan $8 \%$ mahasiswa memilih setuju. Nilai akademik meningkat dengan menggunakan private speech dengan pengaturan diri yang baik, sebanyak $17 \%$ mahasiswa sangat setuju dan 58\% mahasiswa setuju serta $25 \%$ mahasiswa kurang setuju. Private speech dilakukan ketika merasa kesulitan dalam melakukan pemecahan masalah, sebanyak 25\% memilih sangat setuju, 42\% setuju dan 33\% kurang setuju. Self-regation berpengaruh terhadap nilai akademik sebanyak 33\% memilih sangat setuju, $42 \%$ setuju dan $25 \%$ kurang setuju.
\end{abstract}

Kata Kunci : Private Speech, Self-Regulation, Pemecahan Masalah

\section{PENDAHULUAN}

Private speech pertama kali

diperkenalkan oleh dua tokoh psikologi yaitu
Lev Vygotsky dan Jean Piaget (Gholami et al., 2016). Vhgotsky mengemukakan pada usia dini anak-anak telah mempelajari secara luas 
mengenai private speech, jadi dapat disimpulkan private speech selalu doitemui pada masa kanak-kanak (Davis et al., 2013) tapi private speech tidak hanya terjadi pada masa kanak-kanak jelas bahwa orang dewasa juga mengalami private speech (Alarcón-Rubio et al., 2013) Pada masa kanak-kanak, anak-anak sering berbicara dengan mengeluarkan suara secara lentang kepada diri sendiri saat dihadapkan dengan berbagai persoalan dalam suatu kegiatan, seiring bertambahnya usia penggunaan private speech pada masa dewasa menjadi semakin sulit untuk dipahami karena bentuk private speech yang digunakan mahasiswa menjadi lebih tenang atau dapat mudah dikendalikan, dimana mahasiswa cenderung menggunakan bentuk private speech dengan cara berbisik dan bergumam dengan nada suara rendah (Davis et al., 2013).

Private speech merupakan ungakapan diri mahasiswa yang ditunjukan pada diri sendiri, jadi mahasiswa diibaratkan berbicara pada dirinya sendiri. Proses tersebut dilakukan oleh mahasiswa tanpa adanya niat untuk berkomunikasi dengan orang lain (Gholami et al., 2016). Private speech merupakan salah satu cara penting yang dilakukan dalam mencerminkan self-regulation mahasiswa, dapat digunakan untuk mengatur perilaku mahasiswa untuk selalu fokus dalam melakukan pemecahan masalah (Day \& Smith, 2018; Gheisari, 2017). Panduan perilaku ini juga relevan dengan self-regulation emosi mahasiswa (Day \& Smith, 2018) dan dengan demikian juga ditemukan private speech berhubungan dengan Self-Regulation emosi sebagai alat mediasi dalam regulasi kognitif mahasiswa selama menyelesaikan tugas dan masalah matematika (Gheisari, 2017) serta lebih mendominasi dalam peningkatan kualitas pembelajaran matematika mahasiswa (Salahuddin et al., 2020).

Private speech memiliki korelasi yang tidak dapat dipisahkan dengan hasil belajar mahasiswa (Al-Namlah et al., 2006) pada berbagai penyelesaian masalah baik bersifat kognitif (Alarcón-Rubio et al., 2013; Davis et al., 2013; Gholami et al., 2016) dan menjadi salah satu cara alternatif yang efektif untuk mendukung kinerja mahasiswa dalam proses pembelajaran berlangsung (Zimmermann \& Brugger, 2013). Terdapat berbagai bentuk private speech yang digunakan orang dewasa dalam melakukan pemecahan masalah, namun yang sering muncul pada orang dewasa adalah berbentuk gumaman dan bisikan dengan nada suara rendah (Davis et al., 2013; Lidstone et al., 2010).

Faktor pendorong terjadinya private speech pada mahasiswa adalah ketika mahasiswa merasa kesulitan dalam menghadai tugas-tagas baru serta ketika mahasiswa dihadapkan dengan tugas yang membutuhkan proses pemikiran tingkat tinggi dalam menyelesaikan pemecahan masalah (AlarcónRubio et al., 2013; Gheisari, 2017) misalnya dalam literasi (Davis et al., 2013) atau melakukan penyelesaian soal dalam pemecahan masalah matematika (Salimi, 2016).

Pemecahan masalah merupakan salah satu aktivitas kognitif yang sangat penting untuk perkembangan proses berpikir mahasiswa, dimana standar pembelajaran matematika menganggap pemecahan masalah sebagai bagian yang tidak dapat terpisahkan dari proses belajar mengajar dalam matematika (Aljaberi \& Gheith, 2016). Terdapat beberapa keterampilan yang harus dimiliki oleh mahasiswa dalam melakukan pemecahkan masalah matematika yaitu keterampilan berpikir tingkat tinggi dan berpikir kreatif (Ramdhani et al., 2020), sehingga dapat membantu mahasiswa dalam menghadapi persoalan-persoalan yang konkret di masa depan dan proses pembelajaran dan pengajaran akan berlangsung secara optimal dengan adanya kemampuan yang dimiliki oleh mahasiswa (Juliawan et al., 2020).

Tujuan utama pengajaran matematika adalah mengembangkan pemikiran bagi mahasiswa, baik kritis maupun kreatif berpikir tingkat tinggi(Ramdhani et al., 2020) (Demitra, 2018). Ketika mahasiswa mengemukakan suatu masalah, maka mahasiswa harus berpikir, memeriksa data dari rumusan tersebut, menganalisis rumusannya secara kritis serta menangani strategi pemecahan yang memungkinkan diperolehnya pemecahan masalah sehingga memperoleh solusi(Ayllón et al., 2016). Pada saat melakukan pemecahan masalah matematika terdapat berbagai alternatif cara yang 
dilakukan oleh mahasiswa dalam menemukan solusi atau melakukan pemecahan masalah, salah satunya dengan menggunakan private speech dengan cara pelatihan diri dalam bentuk bacaannya disuarakan dengan suara lantang agar dapat didengar (Salimi, 2016). Terdapat hubungan linear antara private speech dengan kesulitan mahasiswa dalam melakukan pemecahan masalah matematika yang belum teratasi hingga saat ini.

Kenyataan yang ditemukan oleh para penelitian terdahulu bahwa private speech cenderung ditemukan pada mahasiswa yang mengalami kesulitan dalam menyelesaikan pemecahan masalah dan ketika mahasiswa dihadapkan pada tugas-tugas baru yang membutuhkan pemikiran tingkat tinggi sehingga hal tersebut memiliki keterkaitan terhadap selfregulation mahasiswa. Selain terkait dengan tindakan dan perilaku self- regulation terkait pula dengan regulasi emosi mahasiswa (Kellogg, 2010). Self-regulation menekankan komponen perilaku dan emosional yang menunjukkan bahwa selain proses kognitif, emosi dan perilaku prososial juga dapat diarahkan dan dikendalikan (Kuvalja et al., 2013) dengan bantuan private speech yang dilakukan oleh mahasiswa. Self-regulation mengintegrasikan tiga proses yairu proses kognitif, proses perilaku, dan proses regulasi emosional, terutama dalam hal emosi negatif (misalnya frustrasi) ketika hal-hal tidak berjalan seperti yang diharapkan (Ludwig et al., 2016).

Self-regulation definisikan sebagai manajemen akan perhatian, emosi, dan respons yang sesuai dengan keinginan mahasiswa untuk tujuan tindakan yang diarahkan pada tujuan (Kellogg, 2010) Kegagalan mamahasiswa dalam self-regulation akan mengakibatkan masalah dalam perhatian, emosi dan kontrol perilaku mahasiswa (Lynn et al., 2011). Private speech digunakan mahasiswa sebagai sarana pengendalian diri dalam membimbing diri mahasiswa serta melayani fungsi selfregulation (Lidstone et al., 2010). Foktor terjadinya private speech adalah kerena mahasiswa merasa kesulitan dalam meyelesaikan tugas dan kesulitan dalam memahami pembahasan dalam soal yang diberikan (Lechler \& Hare, 2014). Aspek penting dari matematika adalah pemecahan masalah matematika. Pentingnya pemecahan masalah dalam matematika terletak pada tujuan danhasil akhir dari proses belajar dan mengajar (Manizar, 2016).

Telah dilakukan studi pendahuluan oleh peneliti, bahwa terdapat mahasiswa Prodi Informatika yang menggunakan private speech. Hal ini dikarenakan adanya mahasiswa yang menggunakan private speech dalam berbagai bentuk. Dari deskripsi private speech diatas dipandang bahwa peneliti tertarik dalam melakukan penelitian mengenai analisis private speech dalam membantu Self-Regulation pada pemecahan masalah matematika mahasiswa Prodi Infrormatika. Secara umum penelitian bertujuan untuk mendeskripsikan private speech dan mengeksplorasi private speech dalam membantu Self-Regulation pada pemecahan masalah matematika mahasiswa Prodi Informatika.

\section{METODE PENELITIAN}

Jenis penelitian ini adalah deskriptif dengan pendekatan kualitatif. Penelitian ini dilaksanakan di STKIP Harapan Bima pada program studi Pendidikan Informatika pada semester 2 sebanyak 50 mahasiswa. Subjek yang dipilih dalam penelitian ini adalah dua belas mahasiswa. Pengambilan subjek dalam penelitian ini berdasarkan hasil observasi awal. Instrumen Penelitian;

1) Peneliti dalam penelitian ini merupakan instrumen utama dalam pelaksanaan penelitian. Hal ini dikarenakan peneliti berperan sebagai pencari dan pengumpul data langsung dari sumber data.

2) Tes digunakan sebagai instrumen pendukung yang bertujuan untuk mengetahui private speech serta selfregulation mahasiswa. Soal yang digunakan yaitu Barisan Aritmatika.

3) Wawancara secara mendalam di gunakan untuk mengetahui private speech mahasiswa dan self-regulation. Wawancara menjadi salah satu instrumen penting. Wawancara yang digunakan merupakan wawancara tidak terstruktur. Tujuannya adalah untuk mendukung data yang diperoleh dari hasil observasi dan rekaman 
audio visual pada saat mahasiswa melakukan pemecahan masalah matematika.

4) Angket digunakan untuk mengungkap fakta, karena satu angket dapat mengungkap informasi mengenai banyak hal. Angket berisi pernyataan yang bernilai Sangat Setuju, Setuju , Tidak Setuju, dan Sangat Tidak Setuju. Pertanyaan pada angket bersifat langsung mengarah pada informasi.

5) Observasi dan Rekaman Audio Visual pada penelitian ini digunakan untuk mengetahui informasi yang lebih mendalam mengenai private speech dan self-regulation dengan disertai pencatatan-pencatatan terhadap keadaan atau prilaku subjek. Pengamatan dan pencatatan secara sistematis fenomenafenomena yang diselidiki agar tidak ada informasi yang terlewatkan maka proses mahasiswa dalam melakukan pemecahan masalah berupa soal tes uraian dan proses wawancara direkam menggunakan rekaman audio visual.

Tekhnik analisis data; 1. Proses reduksi data dalam penelitian ini yaitu: (a) merangkum hasil wawancara, hasil angket dan observasi peneliti yang berupa catatan atau rekaman informasi dari narasumber, (b) memilah-milah data yang penting dan kurang penting, (c) data yang penting dikaitkan dengan proses private speech dan self-regulation mahasiswa, karena pada intinya wawancara, angket, observasi serta rekaman audio visual ini digunakan untuk mendapatkan informasi yang mendalam mengenai private speech dan self-regulation mahasiswa; 2. Penyajian data dalam penelitian ini bersifat naratif, membantu untuk memahami sesuatu yang sedang terjadi, langkah selanjutnya melakukan analisis mendalam berdasarkan pemahaman terhadap data yang disajikan. Penyajian data dalam penelitian ini berdasarkan hasil dari reduksi data. Data yang sudah direduksi disajikan dalam bentuk uraian atau teks naratif; 3. Peneliti akan mengemukakan kesimpulan penelitian yang didukung oleh data yang valid, dengan demikian dari hasil analisis kemudian disimpulkan berupa data temuan, sehingga dapat menjawab permasalahan dalam penelitian ini. Pada tahap ini kesimpulan yang dipaparkan peneliti berdasarkan semua hasil analisis semua data yang diperoleh.

Keabsahan menggunakan triangulasi metode yaitu menggunakan wawancara, angket, observasi serta diperkuat dengan menggunakan rekaman audio visual.

Prosedur penelitian; 1) Persiapan Penelitian. Peneliti melakukan observasi awal dan menyiapkan surat izin penelitian kepihak kampus serta melakukan komunikasi dengan pihak kampus; 2) Pelaksanaan Penelitian. Pada tahap pelaksanaan, peneliti melakukan observasi awal dengan memberikan tes yang digunakan sebagai alat pendukung. Pada tahap observasi awal ditemukan dua belas orang mahasiswa yang menggunakan private speech. Selanjutnya tahap penelitian, Peneliti memberikan soal kepada mahasiswa dan melakukan wawancara serta pembagian angket yang dilakukan pada waktu yang bersamaan. Tahap observasi awal dan tahap pelaksanaan dilakukan pada waktu yang berbeda. Saat mahasiswa melakukan pemecahan masalah peneliti melakukan dokumentasi, observasi dan menggunakan rekaman audio visual agar tidak ada informasi yang terlewatkan; 3) Pembuatan Laporan Penelitian. Pada tahap akhir penelitian adalah membuat laporan secara tertulis yang berupa hasil dari analisis data yang berkenaan dengan private speech dalam membantu SelfRegulation pada pemecahan masalah matematika mahasiswa prodi Informatika yang dipaparkan dalam bentuk deskriptif.

\section{HASIL PENELITIAN}

Berdasarkan analisis terhadap subjek yang terpilih yaitu 12 subjek penelitian diantaranya menggunakan beragam bentuk private speech. Ada yang menggunakan dengan volume suara keras dan ada yang volume suara rendah.

Dalam penelitian yang berjudul Analisis PS dalam membantu self-regulation pada pemecahan masalah matematika mahasiswa Prodi Informatika, sumber data diperoleh dari observasi awal. Dalam fenomenanya private speech biasanya terjadi pada anak-anak rentang usia 1-12 tahun, namun pada kenyataan private speechpun terjadi pada orang dewasa. Terdapat 12 mahasiswa dari 50 mahasiswa 
prodi informatika yang menggunakan private speech. 12 orang mahasiswa terdiri dari 5 orang wanita dan 7 orang laki-laki.

Pada Hasil wawancara, dari 12 Subjek penelitian yang diteliti akan diwakilkan oleh 6 orang mahasiswa dikarenakan jawaban atas pertanyaan observasi secara keseluruhan subjek menjawab dengan inti yang sama. Maka peneliti hanya memaparkan 6 dari 12 hasil wawancara dan pemecahan masalah yang telah dilakukan bersama mahasiswa.

1. Hasil pemecahan masalah dan wawancara mahasiswa

a) Hasil pemecahan masalah dan wawancara mahasiswa $P_{1} \& P_{2}$

- Hasil pemecahan masalah

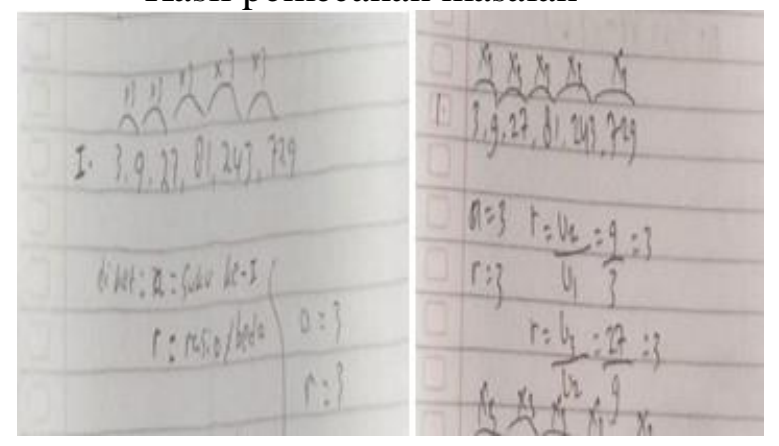

Gambar : 1 dan 2

- Hasil Wawancara $P_{1}$

$O$ : "Apakah anda menyadari selama menyelesaikan soal menggunaan private speech??"

$P_{1}$ : "Iya bu"

$O$ : "Kenapa anda berbicara pada diri sendiri ??"

$P_{1}$ :" Karena Kebiasaan. Biar fokus, biar lebih mudah"

$O$ : "Bagaimana perasaan anda saat berbicara pada diri sendiri?"

$P_{1}$ : "Saya senang bu, nyaman. Kalau gak ngomong dan gak gerak malah gak bisa"

$O$ : "Sejak kapan anda menggunakan Private Speech?"

$P_{1}$ : "Sejak SMA"

$O$ : "Apakah kamu bisa memahami soal dan melakukan pmecahan masalah saat menggunakan Private Speech?"

$P_{1}$ : "Bisa ni ibu, saya jadinya lebih cepat kerjakan soal. Cuman saya gak suka diganggu ibu, kalau diganggu malah membuat saya lupa"

- Hasil Wawancara $P_{2}$
$O$ : "Apakah anda menyadari selama menyelesaikan soal menggunaan private speech??"

$P_{2}$ : "Tidak, Keluar sendiri saja. Saya malah baru sadar bu"

$O$ : "Kenapa anda berbicara pada diri' sendiri ?"

$P_{2}$ : "Gak tau, kalau gak ngomong ya lupa aja apa yang dilakukan"

$O$ : "Bagaimana perasaan anda saat berbicara pada diri sendiri?"

$P_{2}$ : "Senang, nyaman. Kalau gak ngomong gak gerak malah gak 'bisa",

$O$ : "Sejak kapan anda menggunakan Private Speech?"

$P_{2}$ : "Kurang tau bu, saya gak sadar. Tapi kadang memang digunakan biar memahami."

$O$ : "Bagaimana proses belajar yang anda sukai ?"

$P_{2}$ : "Suka belajar tanpa adanya keributan. Saya itu gak bisa di ganggu bu. Gak bisa saya belajar yang ada hilang semua diotak saya"

b) Hasil pemecahan masalah dan wawancara mahasiswa $P_{3} \& P_{4}$

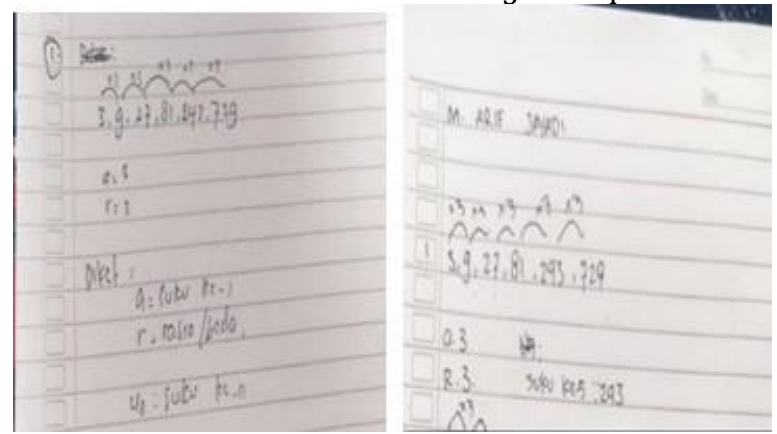

\section{Gambar : 3 dan 4}

- Hasil Wawancara $P_{3}$

$O$ : "Apakah anda menyadari selama menyelesaikan soal menggunaan private speech??"

$P_{3}$ : "Iya bu, Saya malah udah terbiasa gak tau kenapa"

$O$ : "Kenapa anda berbicara pada diri' sendiri ?"

$P_{3}$ : "sudah terbiasa bu. Suka saja tapi tiba-tiba langsung keluar aja suaranya"

$O$ : "Bagaimana perasaan anda saat berbicara pada diri sendiri?"

$P_{3}$ : "Nyaman aja bu. Karena terbiasa ya bu jadi ya begitu"

$O$ : "Sejak kapan anda menggunakan Private Speech?"

$P_{3}$ : "Saya dari kecil memang suka gtu bu, tapi pelan-pelan."

$O$ : "Bagaimana proses belajar yang anda sukai ?"

$P_{3} \quad$ : "Suka belajar sambil dengarin musik, tapi kalau ada oranag ribut disamping saya terganggu" 
- Hasil Wawancara $P_{4}$

$O$ : "Apakah anda menyadari selama menyelesaikan soal menggunaan private speech??"

$P_{4}$ : "Kadang-kadang bu"

$O$ : "Kenapa anda berbicara pada diri' sendiri?"

$P_{4}$ : "ya karena saya suka, saya lebih konsentrasi kalau ngomong begitu"

$O$ : "Bagaimana perasaan anda saat berbicara pada diri sendiri?"

$P_{4}$ : "Lebih kepada senang bu, saya kalau ngomong sendirimalah jadinya lebih konsen sama soal. Buat ngeladenin orang atau teman disamping saja gak punya waktu. Bisa mengontrol amarah saya juga bu"

$O$ : "Sejak kapan anda menggunakan Private Speech?"

$P_{4}$ : "Sejak SMA. Itu yang saya sadari"

$O$ : "Bagaimana proses belajar yang anda sukai?"

$P_{4} \quad$ : "Mendengakan Musik, Mendengar sambil melihat. Audio visual bu jadi seimbang"

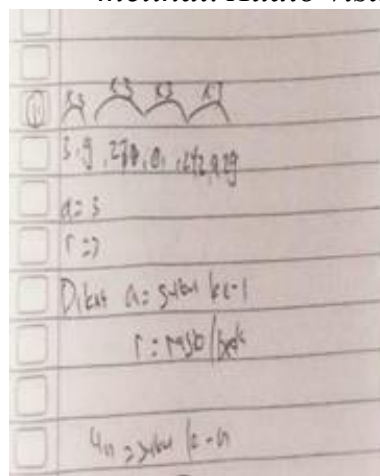

c) Hasil pemecahan masalah dan wawancara mahasiswa $P_{5} \& P_{6}$

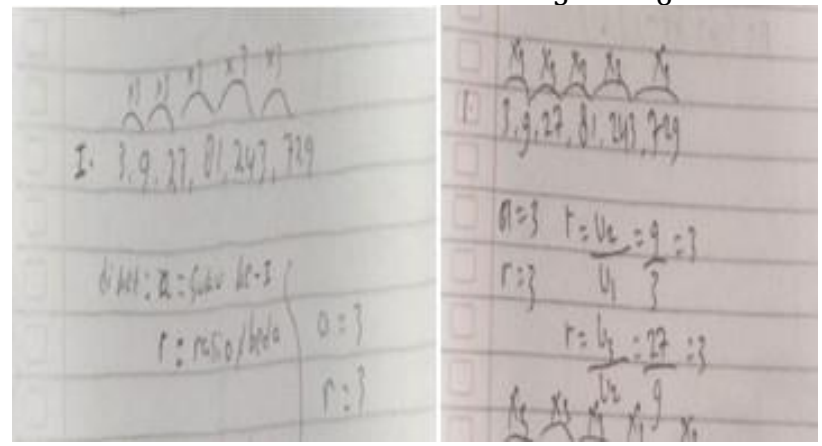

Gambar : 5 dan 6

- Hasil Wawancara $P_{5}$

$O$ : "Apakah anda menyadari selama menyelesaikan soal menggunaan private speech??"

$P_{5}$ : "iya, sudah dari dulu memang saya kalau ada soal-soal atau memahami soal selalu mengelurakan suara"

$O$ : "Kenapa anda berbicara pada diri' sendiri ?"
$P_{5}$ : "Karena Nyaman aja bu pokoknya gak bisa kalau gak keluarkan suara. Tapi kalau diam lagi malah lebih gak bisa,"

$O$ : "Bagaimana perasaan anda saat berbicara pada diri sendiri?"

$P_{5}$ : "Biasa sih bu. Gak ada marah, gak ada beban. Bisa lancar aja kerjanya kalau sambil ngomong tu"

$O$ : "Sejak kapan anda menggunakan Private Speech?"

$P_{5}$ : "Sejak SMA, Tapi pernah waktu kecil tu teman saya merasa terganggu dengan ucapan yang saya keluarkan. Tapi saya tidak bu"

$O$ : "Bagaimana proses belajar yang anda sukai ?"

$P_{5} \quad$ : "Kayak biasanya aja bu, yang penting ada contoh soal. Suka lebih besar suaranya kalau soalnya lebih sulit bu

- Hasil Wawancara $P_{6}$

$O$ : "Apakah anda menyadari selama menyelesaikan soal menggunaan private speech??"

$P_{6}$ : "Gak bu, keceplosan aja.Kadang sadar kadang gak tau"

$O$ : "Kenapa anda berbicara pada diri' sendiri ?"

$P_{6}$ : "Untuk mengendalikan pikiran dan emosi aja bu. jad"i lebih paham

$O$ : "Bagaimana perasaan anda saat berbicara pada diri sendiri?"

$P_{6}$ : "Menggunakan private speech sangat membuat saya nyaman, bisa mengendalikan kesulitan atau kekesalan saat saya belum menemukan jawaban"

$O$ : "Sejak kapan anda menggunakan Private Speech?"

$P_{6}$ : "Saya dari kecil memang sudah terbiasa bu, hanya bergumam."

$O$ : "Bagaimana proses belajar yang anda sukai ?"

$P_{6}$ : "Suka pembelajaran mendengrkan sambil melihat. Tapi ketika saya tidak mendengar sesuatu ya itu saya mengeluarkan suara dengan nada rendah. Trus saya tanya keteman saya bu, dia dengar gak suara saya, ternyata dia mendengar tapi tidak merasa terganggu. Ada juga yang terganggu tapi pelan padahal. Kalau orang di dekat saya ngomong apa ya saya tidak memahaminya. Karena konsentrasi saya sama pekerjaan saya

Dari hasil wawancara dengan mahasiswa, keseluruhan mahasiswa yang menggunakan private speech merasa private speech sangat dapat membantu peran self regulation, membantu mahasiswa secara daya 
ingat menjadi lebih kuat. Lebih merasa percaya diri, dan membantu agar lebih berkonsentrasi.

Pada penggunaan private speech ternyata laki-laki lebih dominan melakukan private speech hal ini bertolak belakang dengan pendapat Salimi (2016) yang mengemukakan private speech tidak berdampak pada kinerja siswa laki- laki dalam menyelesaikan masalah matematika. Sedangkan hasil yang diperoleh dalam penelitian ini nyatanya private speech sangat berdampak positif bagi mahasiswa lakilaki, berupa meningkatkan tingkat konsentrasi, lebih memahami dan meningkat nilai atau prestasi begitupun dengan hasil penelitian yang telah diteliti oleh peneliti dalam penelitian ini. Penggunaannya private speech sangat berperan dalam membantun self regulation mahasiswa. Dominan private speech terjadi pada mahasiswa laki-laki. Sejalan dengan hasil penyelesaian mahasiswa pada saat melakukan pemecahan masalah matematika.

Private speech dalam membantu self regulation yaitu berperan sebagai salah satu strategi belajar mahasiswa yang merasa kesulitan dalam memahami pemecahan masalah. Penggunaan private speech telah menjadi kebiasasaan bagi mahasiswa. Tak jarang banyak dari mahasiswa yang tidak merasa bahwa penerapan strategi proses belajarnya menggunakan private speech dengan berbagai bentuk. Bentuk private speech yang digunakan mahasiswa dapat dilakukan berbagai cara, yaitu ada yang menggunakan private speech dengan menggunakan suara keras, bergumam ataupun dengan volume suara yang kecil dengan selalu menggerakan anggota tubuh. Penggunaan private speech dalam pemecahan masalah mahasiswa karena mahasiswa melakukan self regulation untuk meningkatkan konstrasi, fokus dan agar lebih memahami permasalahan speech telah menjadi kebisaan yang secara spontan terjadi.

Private speech memiliki peran sebagai kontrol akan self regulation mahasiswa. Telah menjadi kebiasaan yang bahkan dengan self regulation yang baik akan menjadi kebiasaan yang baik pula dalam sikap dan prilaku atas keseharian mahasiswa. Dengan kata lain private speech berkorelasi positif akan self regulatian prilaku sikap mahasiswa dalam kehidupan sehari-hari, sejalan dengan pendapat (AlarcónRubio et al., 2013; Davis et al., 2013; Gholami et al., 2016) Siswa yang menggunakan private speech mengungguli baik secara akademik maupun sosial. Lebih Penggunaan private speech sangat menjajikan keberhasilan bagi mahasiswa baik pada masa sekarang maupun yang akan datang, private speech sangat memiliki pengaruh positif terhadap selfregulation, karna private speech berperan sebagi pengendali atas kontrol sikap pengaruh prilaku mahasiswa kearah yang lebih baik.

\section{Hasil Angket Mahasiswa}

Dalam mengisi Angket terdapat perbedaan dari berbagai mahasiswa. Ada yang mengisi sangat setuju, setuju, kurang setuju dan ada yang memilih sangat tidak setuju. Dengan memperhatikan berbagai kejadian yang dialami oleh mahasiswa itu sendiri. Berikut hasil angket yang berkaitan dengan penelitian yang dilakukan oleh peneliti.

Tabel 1. Hasil pengisian Angket Mahasiswa

\begin{tabular}{|c|c|c|c|c|}
\hline \multirow{2}{*}{ No } & SS & S & KS & TS \\
\hline 1 & 4 & 8 & & \\
\hline 2 & 5 & 7 & & \\
\hline 3 & 4 & 8 & & \\
\hline 4 & 5 & 4 & & 3 \\
\hline 5 & 5 & 7 & & \\
\hline 6 & 4 & 3 & & 5 \\
\hline 7 & 3 & 3 & 1 & 8 \\
\hline 8 & & 7 & 2 & \\
\hline 9 & 11 & 1 & & 8 \\
\hline 10 & 2 & 7 & 3 & \\
\hline 11 & 3 & 5 & 4 & \\
\hline 12 & 4 & 5 & 3 & \\
\hline 13 & & & 4 & \\
\hline
\end{tabular}

Tabel 2. Persentase Hasil Pengisian Angket Mahasiswa

\begin{tabular}{|c|c|c|c|c|}
\hline \multirow{2}{*}{ No } & \multicolumn{4}{|c|}{ Persentase \% } \\
\cline { 2 - 5 } & SS & S & KS & TS \\
\hline 1 & 33 & 67 & & \\
\hline 2 & 42 & 58 & & \\
\hline
\end{tabular}




\begin{tabular}{|c|c|c|c|c|}
\hline 3 & 33 & 67 & & \\
\hline 4 & 42 & 33 & & 25 \\
\hline 5 & 42 & 58 & & \\
\hline 6 & 33 & 25 & & 42 \\
\hline 7 & & 25 & 8 & 67 \\
\hline 8 & 25 & 58 & 17 & \\
\hline 9 & & & 33 & 67 \\
\hline 10 & 92 & 8 & & \\
\hline 11 & 17 & 58 & 25 & \\
\hline 12 & 25 & 42 & 33 & \\
\hline 13 & 33 & 42 & 25 & \\
\hline
\end{tabular}

Berdasarkan hasil Angket diperoleh bawa Materi Pelajaran Barisan dan Deret merupakan salah satu mata pelajaran yang penting untuk diajarkan, sebanyak 33\% mahasiswa memilih setuju, 67\% yang setuju penggunaan private speech dalam pemecahan masalah sangat mebantu proses KBM, 33\% memlilih sangat setuju, $67 \%$ memilih setuju, self-regulation terjadi secara spontan hasil angket mahasiswa terdapat $42 \%$ mahasiswa memlih sangat setuju dan 58\% memilih setuju. Pada saat private speech terjadi secara Spontan terdapat 33\% memlilih sangat setuju, 67\% memilih setuju.

Mahasiswa yakin penggunaan private speech membuat mahasiswa lebih paham materi pelajaran sebanyak $42 \%$ sangat setuju, 33\% smemilih setuju dan $25 \%$ memilih tidak setuju. Mahasiwa merasa terganggu menggunakan private speech sebanyak $25 \%$ merasa setuju, $8 \%$ kurang setuju dan $67 \%$ mersa sangat tidak setuju. Hal ini lebih didominasi oleh mahasiswa yang tidak setuju dengan pernyataan tersebut. Mahasiswa tidak terbiasa Menggunakan private speech sebanyak $25 \%$ setuju, $8 \%$ kurang setuju dan $67 \%$ tidak setuju. Mahasiswa selalu mengerjakan tugas dengan penuh tanggung jawab dan tepat waktu dengan menggunakan private speech, sebanyak $25 \%$ mahasiswa memilih sangat setuju, 58\% memilih setuju dan $17 \%$ memilih kurang setuju. Penggunaan private speech Membuat mahasiswa malas belajar yaitu sebanyak 33\% mahasiswa kurang setuju dan $67 \%$ mahasiswa tidak setuju. Selfregulation yang baik membuat mahasiswa fokus dalam menyelesaikan soal, sebanyak $92 \%$ mahasiswa memilih sangat setuju dan $8 \%$ mahasiswa memilih setuju. Nilai akademik meningkat dengan menggunakan private speech dengan pengaturan diri yang baik, sebanyak $17 \%$ mahasiswa sangat setuju dan 58\% mahasiswa setuju serta $25 \%$ mahasiswa kurang setuju.

Private speech dilakukan ketika merasa kesulitan dalam melakukan pemecahan masalah, sebanyak $25 \%$ memilih sangat setuju, $42 \%$ setuju dan $33 \%$ kurang setuju. Self -regulation berpengaruh terhadap nilai akademik sebanyak $33 \%$ memilih sangat setuju, $42 \%$ setuju dan $25 \%$ kurang setuju.

\section{KESIMPULAN}

Dari hasil penelitian dan pembahasan, maka dapat disimpulkan sebagai berikut:

Private speech dalam membantu self regulation yaitu berperan sebagai salah satu strategi belajar mahasiswa yang merasa kesulitan dalam memahami pemecahan masalah. Penggunaan private speech telah menjadi kebiasasaan bagi mahasiswa. Tak jarang banyak dari mahasiswa yang tidak merasa bahwa penerapan strategi proses belajarnya menggunakan private speech dengan berbagai bentuk.

Dari hasil pemecahan masalah dan wawancara dengan mahasiswa, keseluruhan mahasiswa yang menggunakan private speech merasa private speech sangat dapat membantu peran self regulation, membantu mahasiswa secara daya ingat menjadi lebih kuat. Lebih merasa percaya diri, dan membantu agar lebih berkonsentrasi. Pada penggunaan private speech ternyata laki-laki lebih dominan. Private speech memiliki peran sebagai kontrol akan self regulation mahasiswa. Telah menjadi kebiasaan yang bahkan dengan self regulation yang baik akan menjadi kebiasaan yang baik pula dalam sikap dan prilaku atas keseharian mahasiswa. Dengan kata lain private speech berkorelasi positif akan self regulatian prilaku sikap mahasiswa dalam kehidupan sehari-hari

Hasil Angket menunjukan bahwa persentasi tertinggi yaitu lebih mendominasi 
dimana mahasiswa merasa penggunaan private speech sangat membantu dalam proses pembelajaran berlangsung. Self- regulation yang baik membuat mahasiswa fokus dalam menyelesaikan soal, sebanyak $92 \%$ mahasiswa memilih sangat setuju dan $8 \%$ mahasiswa memilih setuju. Nilai akademik meningkat dengan menggunakan private speech dengan pengaturan diri yang baik, sebanyak 17\% mahasiswa sangat setuju dan 58\% mahasiswa setuju serta $25 \%$ mahasiswa kurang setuju.

\section{SARAN}

a. Untuk penelitian selanjutnya menganalisis secara mendelama mengenai private speech dalam pada berbagai kondisi. Membandingkan antara mahasiswa yang menggunakan private speech dengan mahasiswa yang tidak menggunakan private speech, nilai dan prestasi akademik

b. Menganalisis mengenai self-regulation siswa secara mendalam, keterkaitan antara selfregulation dengan tingkat intelektual mahasiswa

\section{UCAPAN TERIMAKASIH}

Terimakasih kami ucapkan kepada Allah SWT, semua pihak yang telah membantu, yang selalu mensupport hingga terselesaikannya artikel ini. Terkhusus untuk keluarga cinta (Umi Nurhopiyati \& H. Muhdar H.Ahmad), Pimpinan, seluruh partnert kerja dan seluruh Adek-adek mahasiswa prodi Pendidikan Informatika. Semoga artikel ini dapat bermanfaat untuk semua kalangan. Lebih-lebih untuk kemajuan dunia Pendidkan.

\section{DAFTAR PUSTAKA}

Al-Namlah, A. S., Fernyhough, C., \& Meins, E. (2006). Sociocultural influences on the development of verbal mediation: Private speech and phonological recoding in Saudi Arabian and British samples. Developmental Psychology, 42(1), 117-131. https://doi.org/10.1037/00121649.42.1.117

Alarcón-Rubio, D., Sánchez-Medina, J. A., \& Winsler, A. (2013). Private Speech in Illiterate Adults: Cognitive Functions, Task Difficulty, and Literacy. Journal of Adult Development, 20(2), 100-111. https://doi.org/10.1007/s10804-0139161-y

Aljaberi, N. M., \& Gheith, E. (2016). PreService Class Teacher' Ability in Solving Mathematical Problems and Skills in Solving Daily Problems. Higher Education Studies, 6(3), 32. https://doi.org/10.5539/hes.v6n3p32

Ayllón, M. F., Gómez, I. A., \& Ballesta-Claver, J. (2016). Mathematical Thinking and Creativity through Mathematical Problem Posing and Solving. Journal of Educational Psychology - Propósitos y Representaciones, 4(1), 195-218. https://doi.org/http://dx.doi.org/10.2051 1/ pyr2016.v4n1.89

Davis, P. E., Meins, E., \& Fernyhough, C. (2013). Individual differences in children's private speech: The role of imaginary companions. Journal of Experimental Child Psychology, 116(3), 561-571. https://doi.org/10.1016/j.jecp.2013.06.0 10

Day, K. L., \& Smith, C. L. (2018). Maternal behaviors in toddlerhood as predictors of children's private speech in preschool. Journal of Experimental Child Psychology, 177, 132-140. https://doi.org/10.1016/j.jecp.2018.08.0 05

Demitra. (2018). Effects of Handep Cooperative Learning Based on Indigenous Knowledge on Mathematical Problem Solving Skill. International Journal of Instruction, 11(2), 103-114.

Gheisari, N. (2017). Private speech in teacherlearner interactions in an EFL context: A sociocultural perspective. Iranian Journal of Language Teaching Research, 5(2), 53-74. www.urmia.ac.ir/ijltr

Gholami, M., Salehi, N., Azizi, E., \& Fazli, B. (2016). Private Speech And Cognitive Development: A Review Of The Two Theories. Iioab Jurnal, 7(1), 262-269.

Juliawan, R., Fauzi, A., \& Ramdhani, L. (2020). Problematika Pembelajaran Matematika Materi Teorema Pythagoras Berdasarkan Kurikulum 
2013. 6(1), 137-141.

Kellogg, D. (2010). The End of Crocodile Tears , or Child Literature as Emotional Self-Regulation David Kellogg Seoul National University of Education. Journal of Language and Literacy Education, 6(1), 75-92.

Kuvalja, M., Basilio, M., Verma, M., \& Whitebread, D. (2013). Self-Directed Language And Private Gesture In The Early Emergence Of Self Regulation: Current Research Issues. Hellenic Journal of Psychology, 10, 168-192.

Lechler, S., \& Hare, D. J. (2014). The typology and function of private speech in a young man with intellectual disabilities: An empirical case study. Journal of Intellectual Disabilities, 110.

https://doi.org/10.1177/1744629514564 449

Lidstone, J. S. M., Meins, E., \& Fernyhough, C. (2010). The roles of private speech and inner speech in planning during middle childhood: Evidence from a dual task paradigm. Journal of Experimental Child Psychology, 107(4), 438-451. https://doi.org/10.1016/j.jecp.2010.06.0 02

Ludwig, K., Haindl, A., Laufs, R., \& Rauch, W. A. (2016). Self-Regulation in Preschool Children's Everyday Life: Exploring Day-to-Day Variability and the Withinand Between-PersonStructure. Journal of Self-Regulation and Regulation, 02, 98-118.

https://doi.org/10.11588/josar.2016.2.3 4357

Lynn, L. N., Cuskelly, M., O'Callaghan, M. J., \& Gray, P. H. (2011). Self-regulation : A New Perspective on Learning Problems Experienced by Children Born Extremely Preterm. Australian Journal of Educational \& Developmental Psychology, 11, 1-10.

Manizar, E. (2016). Mengelola kecerdasan emosi. Tadrib, 2(2), 1-6.

Ramdhani, L., Fauzi, A., \& widia. (2020). Analisis Kemampuan Berpikir Kreatif Siswa Dalam Pemecahan Masalah
Geometri Ruang. Jurnal Ilmiah Mandala Education, 6(2), 33-42.

Salahuddin, M., Putra, F. P., \& Ramdhani, L. (2020). Pengembangan Media Pembelajaran Matematika Menggunakan Adobe Flash berupa Alur Cerita Anime Pokok Bahasan Aritmatika Sosial. 6(2), 43-50.

Salimi, M. (2016). Effects of Private Speech on Math Problem Solving Performance of Fifth Grade Male Students. Mediterranean Journal of Social Sciences, 7(3), 151-156. https://doi.org/10.5901/mjss.2016.v7n3 s3p151

Zimmermann, K., \& Brugger, P. (2013). Signed Soliloquy: Visible Private Speech. Journal of Deaf Studies and Deaf Education, 261-270. https://doi.org/10.1093/deafed/ens072 